\title{
UMA PROPOSTA DE DIVULGAÇÃO DA ESTRATÉGIA DE ENSINO ESTUDO DE CASO PARA PROFESSORES DE QUÍMICA DO ENSINO MÉDIO
}

\author{
Fernanda Luiza Faria, Ivoni Freitas-Reis \\ Universidade Federal de Juiz de Fora \\ Juiz de Fora, Minas Gerais \\ E-mail: fernandal.defaria@gmail.com, ivoni.reis@ufjf.edu.br
}

\begin{abstract}
Resumo: O trabalho discorre sobre um minicurso realizado para docentes de química que atuam no ensino médio da cidade de Juiz de Fora. O minicurso abordou uma estratégia de ensino baseada na resolução de casos com uma problemática. O estudo retrata como ocorreu o evento, analisa o envolvimento dos docentes na construção e resolução de casos e a percepção deles acerca da aplicabilidade da estratégia de ensino Estudo de Caso. Os resultados mostram que os docentes construíram casos contextualizados e que buscavam relação entre ciência, tecnologia e sociedade. Os participantes destacaram o Estudo de Caso como uma proposta significativa e mostraram interesse em inseri-la no cotidiano da sala de aula, bem como, reconheceram a importância e solicitaram mais eventos de formação continuada.
\end{abstract}

Palavras-chave: formação continuada, educação química, Ensino Médio, estratégia de ensino, estudo de caso.

\section{A PROPOSAL OF DISCLOSURE OF THE TEACHING STRATEGY CASE STUDY FOR CHEMISTRY HIGH SCHOOL TEACHERS}

Abstract: The paper discusses about a short course held for chemistry teachers who work in high school in a city of Juiz de Fora. The short course approach a teaching strategy based on solving cases with a problem. The study report as the event occurred, analyzes the involvement of teachers in the construction and resolution of cases, and their perception about the applicability of Teaching Strategy Case Study. The results show that teachers built contextualized cases and seeking relationship between science, technology and society. The participants highlighted the Case Study as a significant proposal and expressed interest in insert it in their classes and still, recognized the importance and requested more events of continued education.

Keywords: continued education, chemistry education, high school, teaching strategy, case study.

Recebido em 04/05/2015. Publicado em 30/09/2016. 


\section{INTRODUÇÃO}

O ensino tradicional, pautado na aquisição de conhecimento científico, na memorização, no acúmulo de conteúdo e na participação passiva do aluno, ainda é bastante dominante nas escolas. Porém, essa forma de ensino nem sempre permite que o objetivo principal da educação básica seja alcançado: a preparação do aluno para a cidadania.

Chassot (2007) alerta para o fato de que a globalização trouxe novas realidades à educação, repercutindo na necessidade de utilizar formas variadas de ensino. Os alunos possuem, de fato, um número de informações muito mais amplo hoje, pois a tecnologia aumenta superlativamente seu leque de possibilidades. A tendência é que o mundo exterior tecnológico atinja cada vez mais o espaço escolar, sendo necessário que a escola se reorganize para disseminar eficientemente o conhecimento.

É nítido que mudanças na educação básica devem acontecer e de forma mais dinâmica. Os alunos precisam compreender melhor os assuntos que os cercam e as informações que permeiam suas visões de mundo. Os Parâmetros Curriculares Nacionais (PCNs) propõem um ensino contextualizado, interdisciplinar e que promova o desenvolvimento de competências e habilidades importantes. Tal como as outras ciências, o conhecimento químico pode e deve ser capaz de contribuir para essa formação, como o próprio PCN+ (2002) estabelece no seguinte trecho:

A química pode ser um instrumento da formação humana que amplia os horizontes culturais e a autonomia no exercício da cidadania, se o conhecimento químico for promovido como um dos meios de interpretar o mundo e intervir na realidade, se for apresentado como ciência, com seus conceitos, métodos e linguagens próprios, e como construção histórica, relacionada ao desenvolvimento tecnológico e aos muitos aspectos da vida em sociedade (BRASIL, 2002, p. 87).

Mas como atender a esses fatores tão importantes e oportunos ao ensino? Acreditamos que o uso de abordagens inovadoras, com diferentes metodologias de ensino, possa auxiliar nessa mudança. Como exemplo, o enfoque CTS - Ciência, Tecnologia e Sociedade - que tem sido pauta de várias pesquisas realizadas na área de ensino, traz alternativas inovadoras que, se devidamente compreendidas, poderão atender bem à finalidade da educação, ou seja, à formação de cidadãos 
conscientes. Essa corrente do conhecimento busca compreender os aspectos sociais do desenvolvimento da ciência e da tecnologia, de forma a conhecer os benefícios, mas, também, os malefícios que possam trazer (ACEVEDO, 1996; FLÔR, 2007; SANTOS e SCHNETZLER, 2010; SANTOS e MORTIMER, 2001).

Neste contexto, a abordagem CTS é uma opção que deve ser levada para as salas de aula, pois ela engloba questões pertinentes aos âmbitos científico-tecnológico e social. Além disso, essa abordagem tem como uma de suas metas o desenvolvimento de habilidades. Uma possível vertente para o enfoque CTS é a estratégia de ensino por Estudo de Caso. Coerente com os objetivos estabelecidos nessa abordagem (como o de contribuir para a formação de cidadãos), o Estudo de Caso possibilita que os alunos desenvolvam um pensamento crítico, reflexivo e consciente através de questões reais ou fictícias, potencializando uma postura de tomada de decisão (SANTOS e SCHNETZLER, 2010).

\subsection{A Estratégia de Ensino Estudo de Caso (EEEC)}

Diferentemente da metodologia de pesquisa Estudo de Caso, a Estratégia de Ensino Estudo de Caso, aqui discutida, deu-se a partir de uma variação do método Aprendizagem Baseada em Problemas; o qual é conhecido em outros países como Problem Based Learning (PBL), que surgiu no final dos anos sessenta, na Escola de Medicina da Universidade de Mc Master, em Ontário Canadá.

No ensino superior, a EEEC está sendo empregada em cursos como Direito, Administração e Economia. Em Ciências, porém, essa estratégia ainda é pouco adotada (SÁ e QUEIROZ, 2010). Diferentemente dos casos fechados, que são aplicados na Medicina e no Direito, onde há uma resposta correta, nos casos da área da Ciência podem existir várias soluções, visto que neles ocorrem o envolvimento de questões emocionais, econômicas, éticas e políticas, as quais induzem a diferentes abordagens.

Se o emprego da EEEC no ensino superior em Ciências e, mais especificamente, em Química ainda é pequeno, este número apresenta-se bem menor quando se foca no ensino médio. Autoras como Salete Queiroz e Luciana Sá têm apresentado ricas publicações referentes ao Estudo de Caso no ensino superior em Química, e algumas no ensino médio, mostrando o grande potencial desse 
método de ensino (SÁ e QUEIROZ, 2005; SÁ, 2006; BRITO e SÁ, 2010; SÁ e QUEIROZ, 2010; SILVA, OLIVEIRA e QUEIROZ, 2011). A partir disso, propusemo-nos a levantar junto aos docentes que atuam na educação básica as suas potencialidades para o ensino médio.

Após discorrer sobre a origem do Estudo de Caso, é importante trazer a sua definição. Essa estratégia de ensino constitui-se de situações hipotéticas ou verdadeiras, as quais são denominadas casos. Esses casos são oriundos de narrativas sobre os personagens que vivem dilemas e necessitam de uma tomada de decisão. Ao final do caso, os alunos são incentivados a resolvê-lo, procurando a causa do problema abordado e uma solução que julguem como a mais viável.

Segundo Herreid (2004), a EEEC possibilita o desenvolvimento do pensamento crítico, uma vez que exorta a leitura, a argumentação e o desafio. Além disso, sempre permeia um problema social, englobando o cotidiano do aluno. Logo, percebe-se a importância da construção de um caso na aplicação dessa estratégia de ensino.

Herreid (1998a) cita alguns pontos essenciais para a elaboração de um caso. Segundo ele, um bom caso deve contar uma história, a qual deve ser interessante e estar próxima à realidade de quem irá resolvê-lo. Além disso, a história deve ter início e meio; o fim muitas vezes só existirá após as discussões sobre o caso. Este deve centrar-se em um interesse e despertar uma questão. Para isso, ele deve ter um problema e conter drama e suspense.

Outro ponto relevante na elaboração de um caso é a sua atualidade, a fim de despertar um interesse maior no aluno. O fato de criar empatia com os personagens centrais torna a história mais envolvente. Um caso deve ainda incluir citações, as quais dão mais realidade, mais vida e mais drama à história, bem como, ser relevante para o leitor. A narrativa deve trazer situações possíveis de serem enfrentadas pelos alunos, o que pode tornar a sua solução mais interessante e, ainda, ter utilidade pedagógica. Deve provocar conflito, produzir uma discussão, forçar uma decisão: apresentando uma urgência/uma gravidade e exigindo do aluno a proposta de uma solução. Um bom caso deve ter generalidade, ser útil, ter uma aplicabilidade geral. E ainda ser breve, porém, longo o suficiente para relatar os dados pertinentes, tomando o cuidado de não propiciar uma análise tediosa aos estudantes (HERREID, 1998a). 
Graham (2010) também retrata alguns aspectos que devem ser adotados na elaboração dos casos, salientando para a necessidade de instigar a discussão por parte dos grupos de alunos. Para esse autor um bom caso, para o ensino, deve ser:

Aberto, não limitado a apenas uma resposta certa; Conectado a conhecimentos previamente adquiridos ou relevantes, cruciais para os objetivos pedagógicos; Evocativo com questões que provoquem diferentes opiniões, perspectivas e debates; Relevante para a cultura, a conjuntura atual e os objetivos de aprendizagem em pauta; Sustentável, independente de sua extensão, fornecer informações, complexidades e desafios suficientes para que seja proveitoso durante todo o tempo de exercício (GRAHAM, 2010, p.44).

Como podemos observar, as recomendações de ambos os autores conduzem à participação ativa do aluno. Durante a solução dos casos, o estudante identifica o problema, procura informações, analisa as alternativas, levanta hipóteses, encontra possíveis soluções, faz o julgamento dessas e, a partir disso, chega a uma tomada de decisão. Por fim, o estudante ainda deve convencer os demais colegas, através da argumentação, que a solução escolhida é a mais viável.

A análise dos casos pode ser realizada de diferentes maneiras. Herreid (1998b) sugere quatro formatos para a aplicação do Estudo de Caso: tarefa individual, palestra, discussão e atividades em pequenos grupos. Os casos continuam sendo histórias que possuem dilemas; o que muda, nesses diferentes formatos, é o papel do aluno e do professor. Na tarefa individual, o aluno faz a análise do caso sozinho. No formato de palestra, tem-se uma aula expositiva, na qual o professor analisa o caso, define seus objetivos e escolhe um tema controverso para avaliar. Em seguida, expõe os argumentos referentes aos dois lados do problema, defendendo e acusando cada lado ao mesmo tempo.

Nos dois últimos formatos, há uma colaboração entre o professor e o aluno quanto à análise do caso. Na discussão, o professor é quem controla a análise. Ele questiona em diferentes graus a perspectiva do aluno sobre o caso, embora sempre tendo o cuidado de assegurar que o mesmo consiga obter conclusões sobre a análise debatida. Já no último formato, o de pequenos grupos, são os alunos que controlam a análise, e o professor tem o papel de mediador das discussões (HERREID, 1998b). 
Em relação aos quatro formatos, defendemos os dois últimos, nos quais o aluno apresenta participação mais efetiva, o que nos leva a crer que contribuem mais para o seu aprendizado. $O$ formato de discussão tem o benefício de utilizar menos aulas para a sua realização, o que de fato sabemos que é um problema real entre os professores do ensino médio, que visam cumprir com um currículo muito extenso. No entanto, o último formato tem o benefício de os alunos trabalharem em equipe, favorecendo um compartilhamento maior de ideias e a aprendizagem de conteúdos acontece de uma forma mais dinâmica; além de privilegiar valores importantes, como respeito ao próximo, saber ouvir e aceitar as diferenças, dentre outros.

Como uma variante da EEEC, com o formato de pequenos grupos, podemos citar o Caso Simulado. Essa estratégia apresenta um tema controverso, com questões favoráveis e desfavoráveis que englobam um problema social, levando os alunos a investigá-lo e a argumentarem a fim de defenderem suas opiniões, permitindo assim a criação de um debate. O que difere um pouco essa estratégia, em relação aos outros formatos, é a sua organização durante as discussões: há a criação de diferentes personagens envolvidos na questão, os quais são representados pelos alunos. O debate acontece em um cenário de júri, onde cada ator tem um tempo para mostrar seus argumentos e assim acusar ou defender uma ideia. No final, os jurados decidem quem utilizou os melhores argumentos (FLÔR, 2007).

Para Oliveira e Soares (2005), o Caso Simulado, definido em seu trabalho como Júri Químico, pode ser caracterizado como uma atividade lúdica, uma vez que proporciona diversão e prazer. Além disso, eles apontam que, quando essa atividade apresenta regras, ela também pode ser definida como jogo. Durante a execução do Caso Simulado, o debate, que é organizado por meio de atores, pode apresentar regras a fim de que nenhum grupo fique prejudicado. Geralmente, essas regras são referentes ao número de perguntas e de direito à resposta que cada grupo possui para defender suas ideias, bem como, quanto ao tempo de duração das mesmas. As normas são definidas pelo professor.

A partir do que detalhamos aqui, percebemos que a EEEC apresenta grande flexibilidade quanto à sua aplicação, sendo mais um ponto favorável para que o professor a adote em sala de aula. Além disso, compreendemos que essa atividade pode propiciar o aprendizado de conteúdos, bem como, o desenvolvimento de habilidades importantes. Assim, é pertinente ressaltarmos que, por 
mais que os alunos tenham uma participação ativa nesse tipo de atividade, o papel do professor é fundamental para o sucesso da mesma.

\subsection{A formação do professor na adoção de estratégias de ensino diferenciadas}

Como na maioria das estratégias de ensino, o professor assume na EEEC um papel importante desde a etapa inicial, a qual se refere à construção dos casos. Isso porque o tema abordado nos mesmos deve ser contextualizado com o meio em que o aluno vive, permear um problema social e ser relevante dentro do conteúdo da disciplina. Além disso, durante a execução da atividade, é importante que o professor auxilie o aluno na análise dos fatos, na reflexão sobre suas tomadas de decisão e, ainda, que atue como mediador das discussões levantadas, de forma que o debate gerado faça sentido para o estudante.

Uma questão que vem sendo bem discutida, quando se trata de adotar novas metodologias em sala de aula, é se o professor está preparado para isso. Santos e Mortimer (2002) trazem discussões acerca da importância de mudanças significativas na prática e nas concepções pedagógicas do docente, bem como, acerca da relevância da formação docente inicial e continuada, afirmando que não há como desenvolver novos modelos curriculares sem envolver os professores. Logo, para que o educador inove sua prática pedagógica, é necessário que ocorra uma mudança por parte do mesmo, mantendo-se aberto e disposto a aprender como se posicionar frente às novas metodologias de ensino.

Muitos dos profissionais em exercício buscam a formação continuada na esperança de suprir as carências da formação inicial, como muito bem destacam Gil Pérez e Carvalho (2011). Na verdade, a formação continuada cumpre um papel mais amplo, permeando toda a trajetória profissional, sendo essencial para a carreira docente.

Santos et al. (2006) enfatizam a importância da formação continuada através de atividades de extensão, cursos e eventos de capacitação. Entretanto, apontam como premissa que essas atividades foquem sempre a reflexão sobre a prática pedagógica, trabalhando junto com o professor e não para o professor. Para os autores, nessa atividade de reflexão unida ao docente “estabelece-se um trabalho de cooperação na co-construção de recursos e estratégias de ensino a serem desenvolvidas pelo professor" (SANTOS et al., 2006, p. 2). 
Os cursos de formação continuada devem, no entanto, levar em questão os envolvidos no processo de educação, conhecendo o contexto escolar, a cultura escolar, as concepções de professor e aluno (SANTOS et al., 2006). Não basta apenas apresentar propostas de ensino para os educadores, como se as mesmas fossem receitas de sucesso. Esses profissionais precisam ter a experiência de vivenciar a atividade e opinar sobre ela, conhecendo as contribuições que ela pode trazer, mas principalmente, destacar as dificuldades de abordagem da atividade.

Este trabalho traz o relato de uma proposta de divulgação da EEEC através de um minicurso para professores de química do ensino médio da cidade de Juiz de Fora - MG. Para isso, este estudo visa discutir como ocorreu esse minicurso; busca analisar os casos construídos e resolvidos pelos docentes; além de abordar as discussões que permearam o evento em torno, principalmente, da percepção desses sujeitos frente à aplicabilidade dessa atividade no ensino médio.

\section{METODOLOGIA}

O percurso metodológico adotado neste trabalho foi dividido em três momentos distintos: a divulgação, a execução do minicurso (o instrumento de pesquisa utilizado como fonte de dados) e, por fim, a análise dos dados.

\subsection{0 minicurso proferido}

A divulgação do minicurso ocorreu em 27 escolas de ensino médio da cidade, dentre as quais 22 eram estaduais e 5 particulares. O processo se deu por meio de um convite formal à direção dessas escolas, o qual visava conscientizar os dirigentes sobre a importância dos docentes conhecerem a Estratégia de Ensino Estudo de Caso e, consequentemente, esperávamos que eles convidassem e liberassem seus professores para participarem do minicurso. Também foram elaborados cartazes de divulgação, os quais foram afixados em todas as escolas envolvidas.

Com o título "A Estratégia de Ensino Estudo de Caso como proposta para o ensino de Química", o minicurso teve duração de 4 horas e foi realizado no mês de junho de 2012, na Universidade Federal de Juiz de Fora, contando com a presença de 12 professores. O minicurso foi proferido pelas duas autoras desse trabalho. Durante a realização do minicurso procuramos conceituar os procedimentos inerentes, relatando sua origem e mostrando sua aplicação no ensino superior e médio, bem como, discutindo de que forma essa atividade de ensino atende aos PCNs. 
Faria, Freitas-Reis, 2016 - Formação Inicial e Continuada

Inicialmente, definimos e caracterizamos a estratégia de ensino através da visão de vários pesquisadores que têm publicado trabalhos teóricos ou de pesquisa-ação sobre essa proposta de ensino (FLÔR, 2007; HERREID, 1998; HERREID, 2003; SÁ, 2006; SÁ, FRANCISCO e QUEIROZ, 2007; SÁ e QUEIROZ, 2010). Cada participante recebeu uma apostila que continha as instruções para a preparação de um caso investigativo e alguns exemplos de casos. Nela, também foram destacadas as diferentes maneiras de aplicar esse tipo de atividade em sala de aula, a saber: os formatos expositivos, de discussão, individual e em grupo. Além disso, a apostila reservou um espaço para relatos dos alunos do ensino médio, que já haviam realizado essa atividade (FARIA e SILVA, 2012). A seguir, tem-se alguns recortes do material utilizado no minicurso.

Figura 1. Exemplo de um dos casos utilizados no minicurso.

Doença misteriosa em trabalhadores rurais
Mariana é estudante de Administração na Universidade Federal de Viçosa. Na
Fátima semana a faculdade entrou de férias e ela resolveu visitar seus tios Joaquim e
redondezas da cidade. Seu tio Joaquim trabalha no sítio enquanto sua tia Fátima cuida da
quitanda que eles possuem em Coimbra. A quitanda é famosa por vender verduras, frutas
e legumes sempre frescos.
Chegando ao sítio, Mariana encontrou seu tio doente, sua tia disse que após um longo dia de
trabalho, Joaquim acordou no meio da noite, passando muito mal, com muita dor de cabeça, náuseas,
vômitos, tonturas. Além disso, logo pela manha começou a reclamar que estava com dificuldades em
respirar, muito cansaço e com a visão um pouco perturbada. Outros dois trabalhadores do sítio também
estavam com os mesmos sintomas. Preocupada Fátima pediu a Mariana que procurasse algum de seus
amigos que fizessem o curso de química e que estivessem na cidade. Ela então resolveu ligar para eles:
-Alô, Priscila, tudo bem? É a Mariana, quanta saudade! Estou no sítio dos meus tios e estou
precisando da sua ajuda e do Juliano, vocês estão em Coimbra?
- Oi Mari, tudo bem e você? Muita saudade também, você sumiu. Estamos sim, chegamos esse final
de semana. Mas no que podemos ajudar?
- Ah Pri! Meu tio Joaquim e outro dois funcionários do sítio estão doentes, com os mesmos sintomas,
não sabemos a causa, eles não querem ir ao médico, enquanto minha tia tenta convencê-los, gostaria que
vocês me ajudassem a descobrir o que os levaram a ficar doente.
- Entendi. Claro que ajudaremos, vamos marcar hoje á tarde na minha casa, ligarei para o Julianoe
combinarei com ele também. Ai você me explica quais os sintomas. Combinado?
- Combinado. Muito obrigada amiga, até mais tarde então. Um beijo.
vossivel solução para o problema de Joaquim e de seus funcionários.

Fonte: Faria, 2011.

Figura 2. Recorte de parte do Guia para análise dos casos utilizado no minicurso. 


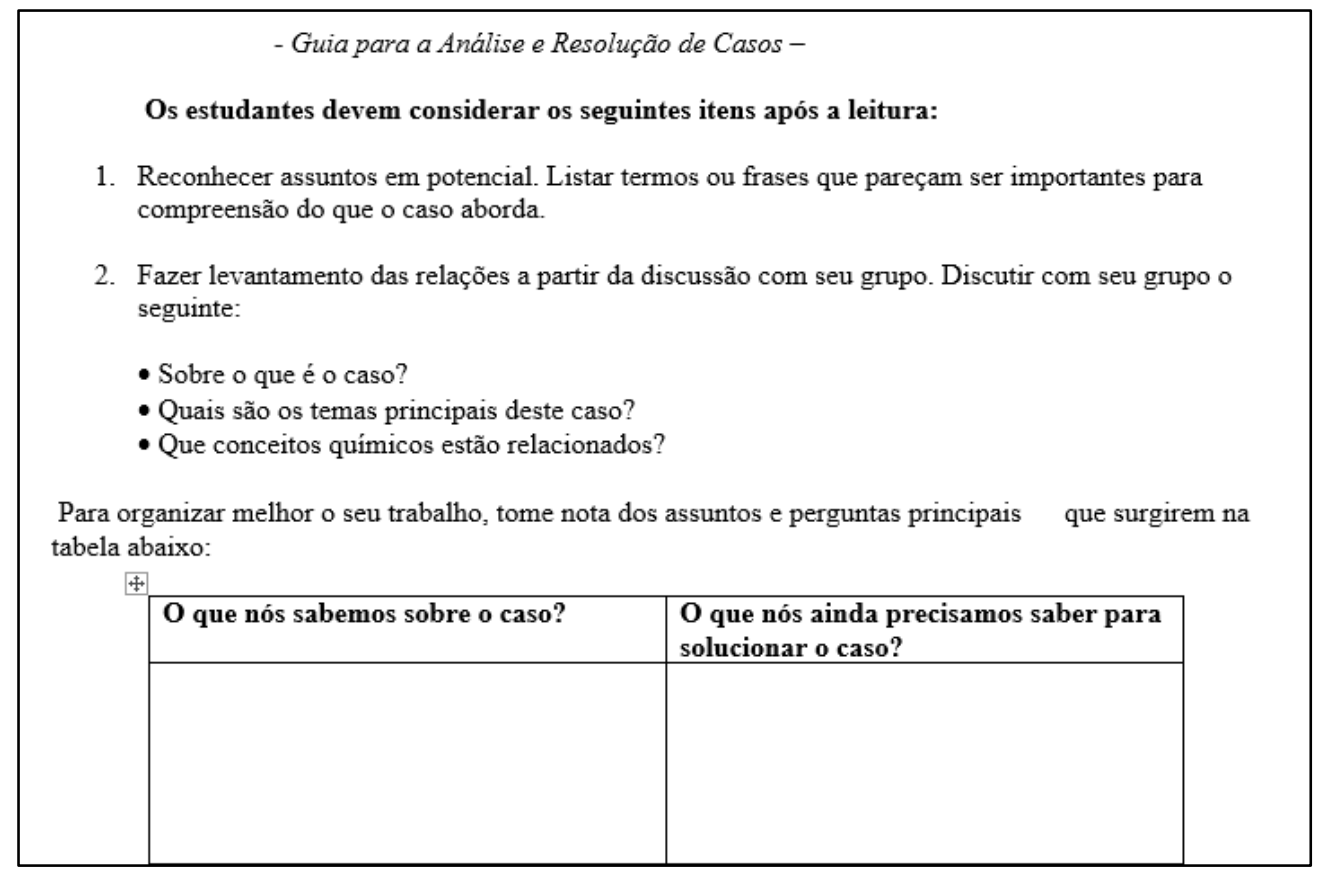

Fonte: Sá e Queiroz, 2010.

Figura 3. Alguns relatos de alunos do ensino médio mostrados no minicurso;

\section{RELATOS DE ALUNOS}

"A apresentação de trabalhos vai estar presente em nossas vidas e esse fez com que a gente perdesse a vergonha". (Comunicação oral)

"A utilização de programas Power Point foi algo muito inovador para mim, pois não tinha idéia alguma de como utilizá-lo". (Utilização de programas computacionais)

"O trabalho ajudou a descobrir maneiras e métodos para a solução de um problema". (Capacidade de solucionar problemas)

Fonte: Faria, 2011.

Após essa etapa sugerimos que, em grupo ou em dupla, os participantes resolvessem um caso. Entendemos que esse passo tem especial relevância, pois é vivenciando uma atividade diferente da rotina que o professor conseguirá compreender melhor os benefícios e, principalmente, as dificuldades da mesma. Assim, ele conseguirá visualizar a posição do aluno frente àquela atividade, o que possivelmente o beneficiará e o ajudará a executar melhor essa estratégia de ensino em suas aulas. 
Seguindo o critério de afinidade, formamos quatro grupos, sendo um grupo de quatro professores, dois grupos de três e uma dupla de professores. Distribuímos quatro casos distintos aos docentes e, através deles, os participantes tiveram que buscar pelo menos uma causa para o problema mencionado na história, propor uma solução viável e definir a quais séries e conteúdos do ensino médio aquele caso se adequaria. A resolução de cada grupo foi apresentada para os demais colegas.

A etapa seguinte consistiu em elaborar um caso com tema livre e apresentá-lo. Uma característica importante, sobre essa ferramenta de ensino, é a liberdade lúdica que os professores dispõem durante a construção dos casos, o que permite que eles inovem e abusem de sua criatividade. Como material de apoio, fornecemos algumas revistas, tais como: Superinteressante, Galileu e Química Nova na Escola.

\subsection{Os instrumentos de pesquisa}

O processo de construção dos dados deu-se em dois momentos distintos, primeiro a partir da observação do minicurso e segundo através da aplicação de um questionário aos participantes. A observação ocorreu durante todo o evento e tinha como objetivo registrar as discussões trazidas pelos professores em torno da EEEC, bem como, as soluções trazidas e os casos propostos pelos grupos de docentes. Gil (1999) defende que a maior vantagem dessa técnica é permitir que os fatos sejam notados de forma direta sem qualquer intermediário.

Segundo Ludke e André (1986) a observação direta pode ser realizada em diferentes graus de participação do pesquisador. Pode-se ter um envolvimento maior no começo da atividade e ir diminuindo sua participação até o final da pesquisa ou ter esse envolvimento mais profundo somente no final. Nessa pesquisa, o envolvimento das pesquisadoras na atividade aconteceu ao longo de todo o minicurso, a fim de instigar e mediar as discussões por parte dos professores. Como forma de registro foi utilizado um gravador, com o consentimento de todos os participantes. Posteriormente as gravações foram transcritas para que as discussões fossem analisadas.

No final do minicurso, foi distribuído um questionário aos participantes com cerca de dez questões, sendo apenas uma delas aberta. A maioria das questões tinha como objetivo conhecer o 
perfil profissional dos participantes. A única questão aberta visava pontuar o motivo que levou esses professores a participarem do evento. Uma das questões fechadas buscava, ainda, verificar se os docentes gostariam de aplicar essa atividade em suas aulas, as quais seriam observadas, em outro momento, pela pesquisadora. Optamos por esta técnica porque favorece o anonimato das respostas, evitando a influência do pesquisador nas respostas dos participantes (GIL, 1999).

\subsection{A análise dos resultados}

O processo de análise requer do investigador uma organização dos dados construídos; a procura de aspectos semelhantes e significativos; interpretação, sintetização e definição do que será discutido (BOGDAN e BIKLEN, 1994). Assim sendo, a análise nesse trabalho é de natureza qualitativa e ocorreu a partir dos dados construídos pelos casos elaborados pelos professores e as discussões trazidas durante o evento, obtidas através das transcrições e das respostas fornecidas nos questionários.

Frente aos casos construídos pelos professores, o tratamento e a análise dos dados ocorreram em duas etapas. Na primeira realizamos um processo de leituras, comparações e interpretações dos casos com os referencias teóricos de Herreid (1998a) e Graham (2010), que trazem apontamentos importantes a respeito do que deve compor um caso investigativo para ser adotado no ensino. $\mathrm{Na}$ segunda etapa, trouxemos apontamentos e discussões sobre a relevância dos temas abordados nos casos para o ensino de química no ensino médio.

Através da análise dos questionários fizemos um levantamento sobre o perfil profissional dos participantes e os motivos que os levaram a aceitar o convite para participarem do evento. A partir das transcrições, abordamos as discussões trazidas pelos professores em torno da Estratégia de Ensino Estudo de Caso, demonstrando os aspectos que os docentes julgaram importantes para a elaboração dos casos; e ainda trechos das falas dos docentes referentes ao momento de resolução dos casos, na qual esses professores atuaram no papel de aluno.

\section{RESULTADOS E DISCUSSÃO}

Os resultados a serem discutidos foram separados em três momentos distintos: os dados atribuídos pelo questionário; as discussões realizadas durante o evento que mereceram destaque; os casos construídos pelos docentes. 
Faria, Freitas-Reis, 2016 - Formação Inicial e Continuada

\subsection{Questionário}

Dentre os 12 professores, 11 deles responderam ao questionário: 7 mulheres e 4 homens, todos licenciados. Mais detalhes, acerca do perfil desses educadores, encontram-se na tabela 1 . Um professor não respondeu ao questionário pelo fato de ter que se ausentar no final do minicurso.

Tabela 1. Perfil profissional dos professores que participaram do minicurso.

\begin{tabular}{|c|c|c|}
\hline Abordagens & Respostas & $\mathbf{N}^{\circ}$ de professores \\
\hline \multirow{2}{*}{ Atuam em escola } & Pública & 10 \\
\hline & Particular & 1 \\
\hline \multirow{3}{*}{ Faixa etária } & 21 a 30 anos & 1 \\
\hline & 31 a 40 anos & 9 \\
\hline & 41 a 60 anos & 1 \\
\hline \multirow{2}{*}{ Regime de contrato } & Efetivo & 9 \\
\hline & Designado-Temporário & 2 \\
\hline \multirow{5}{*}{ Tempo de exercício docente } & 1 a 5 anos & 1 \\
\hline & 6 a 10 anos & 3 \\
\hline & 11 a 15 anos & 3 \\
\hline & 16 a 20 anos & 3 \\
\hline & 21 a 25 anos & 1 \\
\hline \multirow{2}{*}{ Número de escolas que lecionam } & 1 escola & 5 \\
\hline & 2 escolas & 6 \\
\hline \multirow{5}{*}{ Carga horária semanal } & 15 a 20 horas & 2 \\
\hline & 21 a 25 horas & 2 \\
\hline & 26 a 30 horas & 3 \\
\hline & 31 a 35 horas & - \\
\hline & 36 a 40 horas & 4 \\
\hline \multirow{2}{*}{ Possui pós-graduação } & Sim - Especialização & 7 \\
\hline & Não & 4 \\
\hline \multirow{2}{*}{$\begin{array}{l}\text { Já participou de Congressos, Encontros, } \\
\text { Seminários, etc. }\end{array}$} & Sim & 11 \\
\hline & Não & 0 \\
\hline \multirow{2}{*}{$\begin{array}{l}\text { Possui outro tipo de formação } \\
\text { continuada }\end{array}$} & Sim & 1 \\
\hline & Não & 9 \\
\hline
\end{tabular}

Fonte: dados da pesquisa.

A partir dos dados apresentados na tabela, é possível perceber que a maioria dos professores apresenta mais de 10 anos de exercício docente, lecionando, durante a maior parte do tempo, em escolas públicas e com carga horária semanal extensa. Além disso, é notório que grande parte encontra-se preocupada em aperfeiçoar a sua formação, por meio de especializações e participações em congressos, seminários, cursos de capacitação, dentre outros. 
O interesse em realizar essas atividades também pode ser considerado como uma justificativa para a presença desses docentes neste minicurso. Além dessas atividades, um professor citou que também já fez outro tipo de formação continuada, como algumas disciplinas isoladas do mestrado. O interesse dos professores em participar de eventos como esse é significativo, relevante e deve ser enfatizado, pois demonstra a necessidade de que as Instituições de Ensino Superior (IES) ofereçam aos docentes em exercício cursos de formação continuada.

Além de questões referentes ao perfil profissional, havia uma que solicitava aos docentes mencionar o que os motivou a participarem do minicurso. Segue abaixo algumas das respostas elegidas, referenciadas através de nomes fictícios.

Aprender e compartilhar novos conhecimentos práticos e teóricos, com o objetivo de melhorar nosso trabalho e motivação, tanto profissionais como pessoais (professora Helena).

Trocas de ideias para uma melhor qualificação na arte de aprender, ensinar e fazer (professor Pedro).

A oportunidade de enriquecimento e aperfeiçoamento da minha prática profissional (professora Carla).

A possibilidade de conhecimento de novos métodos para o ensino, objetivando atrair mais a atenção dos alunos (professora Aline).

Os relatos acima nos permitem inferir que os professores estão interessados em aprender novas propostas de ensino, com vistas à melhoria da sua prática pedagógica. O que é algo vantajoso, pois várias pesquisas têm relatado a necessidade de formação continuada dos educadores que estão em exercício docente, principalmente quando se busca um ensino que propicie a formação crítica e ativa do aluno. Carvalho e Gil-Pérez (2011) relatam que um dos desejos, ligados à formação básica de um professor, é a busca por entendimento quanto à execução de estratégias de ensino que levem à aprendizagem. Assim, eventos como esse tornam-se cada vez mais importantes, pois buscam auxiliar os professores rumo a essa mudança, contribuindo para o processo contínuo de formação.

\subsection{Discussões ao decorrer do minicurso}


Com relação ao decorrer do minicurso, conforme citado, a primeira tarefa dada aos participantes referia-se à resolução de um caso, de modo que eles deviam encontrar uma causa e uma solução para o problema apresentado, além de citarem qual conteúdo e em que série do ensino médio o aplicaria. O critério de base, para a escolha dos casos utilizados no minicurso, consistiu no fato de serem potencialmente acessíveis a alunos do ensino médio. Os casos utilizados foram construídos pela primeira autora deste trabalho.

Um dos casos tratava de uma notícia fictícia sobre um posto de gasolina que, interditado pela polícia civil, teve tanques, bombas e bicos lacrados. As denúncias partiram de vizinhos e moradores que tiveram problemas, em seus carros, após abastecerem nesse posto. Os problemas citados pelos moradores, no referido caso, foram: aumento de consumo de combustível, dificuldade de dar a partida no automóvel pela manhã, falhas no funcionamento do motor e carcaça da bomba danificada. O caso propõe que os participantes encontrem a causa do problema e sugiram uma possível solução. No trecho abaixo, comentado por um dos professores, o grupo define uma possível causa para o problema:

Nós pensamos o seguinte: nós já ouvimos falar de casos, como o mais recente sobre a adulteração do medidor de volume de alguns postos de combustível de São Paulo, em uma reportagem feita pelo Fantástico (Programa brasileiro exibido todos os domingos na emissora Rede Globo de Televisão). Atendendo a algumas denúncias, o Inmetro (Instituto Nacional de Metrologia, Qualidade e Tecnologia) padronizou um determinado recipiente, com capacidade para 20 litros, e foi a esses postos justamente para verificar se o volume colocado dentro do recipiente era o valor que ele estava medindo; chegando à conclusão de que havia diferença. [...] bom, a questão do volume é uma hipótese. Porém, aqui no texto fala outro detalhe, que é a falha de funcionamento. Aí, nós observamos duas coisas: se for motor a gasolina, ele é projetado para rodar, acho que com no máximo, 20, 21 ou $22 \%$ de teor de álcool na gasolina. Então, nesse caso, daria para fazer esse teste na escola, na determinação de teor de álcool na gasolina. Agora, se for motor flex, ele funciona com qualquer proporção de álcool e gasolina, então talvez fosse colocado ali um determinado tipo de solvente; o qual danifica tanto o motor a álcool quanto o motor a gasolina. Nas citações do caso, a gente optou mais pela questão do solvente, pois ele prejudicaria qualquer tipo de motor. 
Nessa fala é possível observar o levantamento de hipóteses e a análise das alternativas por parte do grupo, trazendo uma causa para o problema, mostrando que os seus participantes entenderam bem a proposta de solucionar o caso. Além disso, destacaram como auxílio para a atividade o uso de um experimento. No próximo trecho o grupo sugere uma solução para o problema do caso:

A solução seria uma fiscalização mais rígida nos postos de gasolina, pois a mesma geralmente é feita no caminhão que está saindo e não diretamente na bomba que é colocado no carro. Ela não é feita diretamente nos postos e, assim, tem-se o problema: a análise pode ser feita no caminhão e verificar que está tudo bem, de modo que o combustível não apresenta solvente, nem excesso de álcool; mas e no trajeto do caminhão até o posto de gasolina perto da sua casa? Nesse meio tempo, ele pode muito bem ser adulterado. Então, se a fiscalização for feita diretamente no posto, essas questões podem ser minimizadas, tanto em relação ao teor de álcool quanto à presença de solventes no combustível.

O grupo debateu bastante em torno do caso, mostrando que a problemática envolvida é um tema polêmico que permite discussões mais amplas em torno de questões econômicas, sociais e éticas. A proposta da EEEC é instigar esse debate em sala de aula a fim de contribuir para a formação de um caráter mais crítico pelo estudante (HERREID, 2004).

Com relação à aplicação desse caso em suas aulas, o grupo relatou que: "a questão do teor de álcool e gasolina poderia ser aplicado no $1^{\circ}$ ano, no estudo sobre as questões de propriedades físicas da matéria, de densidade e de volume; e o solvente no $3^{\circ}$ ano, na parte de química orgânica", estabelecendo assim uma relação entre o problema abordado no caso e o conteúdo químico tratado no ensino médio. O caso se mostrou flexível, podendo ser adotado, na visão dos professores, em mais de uma série do ensino médio. Essa foi a solução de um dos grupos de professores; mas, em geral, todos os grupos encontraram causas e soluções plausíveis, entendendo bem o propósito da atividade. Além disso, todos os docentes perceberam a possibilidade de aplicar os casos em alguma série do ensino médio.

A solução dos casos pelos professores permitiu que eles compreendessem os pontos marcantes da atividade, a finalidade dos casos e a importância de como são construídos. Como destaque, podemos citar que os grupos conseguiram compreender a importância de relacionar os temas dos casos ao cotidiano dos alunos, bem como, abordar questões sociais, éticas e econômicas, aspectos 
que Herreid (1997) considera como essenciais para a construção de uma boa história. Além disso, os participantes destacaram a relação entre o tema, a ciência e a tecnologia. De fato, a EEEC permite ser adotada sob a perspectiva CTS como sugerem Santos e Schnetzler (2010).

Nos trechos abaixo é possível verificar isso. Os dois primeiros comentários referem-se ao grupo que resolveu um caso sobre intoxicação por formol em salões de beleza. E o último comentário pertence ao grupo que resolveu o caso, já mencionado, sobre o posto de gasolina.

É necessário trabalhar mudanças culturais como, por exemplo, aquelas relacionadas aos padrões de beleza. No caso do salão de beleza, a gente pode trabalhar com os alunos o padrão de estética (...) por que as mulheres tendem hoje a ir ao salão para deixar o cabelo liso? Você quer correr o risco de passar mais formol no seu cabelo do que é permitido porque quer ficar no padrão de beleza? Esse é outro "link" que a gente pode fazer com a sociedade. A beleza é mais importante que a saúde?

Para nós, um bom caso tem que ser atual, tem que estar relacionado à mídia. $\mathrm{O}$ aluno tem que estar por dentro do caso e o mesmo tem que estar ligado ao cotidiano do aluno. (...) eu acho que outro fator importante, para um bom caso, é que ele tem que ser simples, pois, se utilizarmos algo hiper ou megacomplexo, podemos acabar nos perdendo na conclusão. Como vamos amarrar aquilo? Então, eu acho que tem que haver simplicidade e tem-se que usar a tecnologia, pois os alunos hoje, não só os alunos, mas a gente também, estão integrados com a tecnologia. Então, tem que ter um link com a tecnologia.

Como características de um bom caso, evidenciamos o envolvimento com questões sociais, econômicas, até mesmo ambientais e éticas; outra característica, que a gente encontrou, foi o caso ser muito atual. Direto a gente vê reportagem sobre posto que foi lacrado por causa disso. Dentro desse caso a gente consegue tirar várias possibilidades da atualidade e do cotidiano do aluno.

Ao longo do minicurso os professores se posicionaram, compartilhando opiniões importantes. A todo momento destacamos sobre a relevância do professor no processo de execução dessa atividade, visto que ele é de extrema importância na construção dos casos, bem como, nas mediações durante as discussões e auxílio durante as soluções pelos alunos. Como bem destaca 
Graham (2010), o professor nessa estratégia não é a fonte da solução, mas sim, o guia do processo.

No decorrer das apresentações dos casos resolvidos, assim como dos casos construídos, os participantes agradeceram o convite para o minicurso, alegando que é importante o contato entre a universidade e os professores da educação básica. Além disso, eles solicitaram a ocorrência de mais oportunidades como essa. Consideramos fundamental o contato destes professores com o que se vem pesquisando na área educacional nas Instituições Superiores de Ensino- as novas estratégias de ensino- pois, só assim, estaremos próximos de alcançar os objetivos educacionais propostos pela Lei de Diretrizes e Bases da Educação Nacional (9.394/96) (Brasil, 1996), e os próprios PCNs que buscam atender a essa lei.

\subsection{Os casos construídos pelos docentes}

Para análise dos casos construídos pelos docentes foi levado em consideração que eles tiveram curto espaço de tempo e uma limitação de materiais para consulta. No entanto, notamos que os grupos utilizaram os pontos principais que estruturam um bom caso investigativo. O que nos leva a entender que eles conseguiram compreender a essência dessa atividade.

A seguir, trazemos as descrições feitas pelos grupos sobre os casos elaborados, as discussões frente aos temas abordados e uma análise dos mesmos sobre a ótica de Herreid (1998a) e Graham (2010):

\subsubsection{Caso 1}

Lilian era uma adolescente comum de 1,70m, pesava $56 \mathrm{~kg}$ e estudava no segundo ano de um colégio em Juiz de Fora. Por ser alta e magra, fazia muito sucesso com os garotos e sua forma física era invejada por suas colegas. Após uma consulta de rotina com o seu médico, um clínico geral, ele Ihe pediu alguns exames e terminou por diagnosticá-la como diabética. Com isso, Lilian teve que passar por uma reeducação alimentar, de modo que, nos intervalos da escola com as amigas, o lanche dela era diferente: enquanto seus amigos comiam só lanches industrializados, Lilian comia frutas. As amigas passaram a questionar o porquê da mudança alimentar, pois Lilian já era muito magra e não precisava alimentar-se de frutas durante o intervalo. 
A dupla de professores chamou atenção para o fato de que os adolescentes não compreendem bem o que é diabetes, acreditando que o problema se deve apenas ao consumo exagerado de doces; enquanto, na verdade, existem vários alimentos que uma pessoa diabética não pode consumir, como aqueles que possuem alto teor de carboidratos: batata, arroz, macarrão, dentre outros. Em seguida, os professores sugeriram ainda que fosse abordada com veracidade as informações disponíveis nos rótulos de alimentos industrializados e, também, que fossem descritos de forma mais compreensível os termos utilizados nesses produtos, visto que os mesmos, muitas vezes, estão em códigos ou em língua estrangeira, dificultando a compreensão por parte dos consumidores.

O grupo ainda ressaltou a possibilidade de relacionar a nutrição com doenças crônicas como diabetes, colesterol alto e obesidade, as quais são assuntos atuais. Não obstante, esse grupo também propôs que os alunos, participantes da atividade, entrevistassem seus colegas durante o intervalo, para saber o que eles comem durante aquele período do dia na escola, bem como, a frequência de consumo de determinados alimentos. Por fim, o trabalho culminaria com uma análise estatística desses dados. A sugestão de trabalho, segundo o grupo de autores, teria aplicação no $1^{\circ}$ ano do ensino médio, relacionando-o ao tema de misturas, e no $2^{\circ}$ ano, para abordar o conteúdo de termoquímica, envolvendo o cálculo de calorias.

Ao analisar o caso construído por esse grupo, foi possível identificar várias características pertinentes aos cuidados na sua elaboração, defendidos por Herreid (1998a), tais como: ser atual e relevante, narrar uma história, produzir empatia com os personagens, ter utilidade pedagógica, provocar conflito, dentre outros. O caso atende ainda aos aspectos citados por Graham (2010), sendo aberto (possibilita que mais de uma solução seja viável) e conectado a conhecimentos relevantes e evocativos, pois permite o embate de opiniões distintas entre os alunos.

O tema proposto permite um debate interessante sobre essas doenças- as quais estão cada vez mais presentes entre os cidadãos - e sobre a alimentação irregular dos adolescentes. Com certeza, trata-se de uma questão social importante para ser discutida em sala de aula. O grupo demonstrou ainda criatividade, atrelando à estratégia de resolução de casos a abordagem de rótulos e a enquete por parte dos estudantes em relação à alimentação dos demais colegas de escola, o que é uma ideia muito interessante, pois acreditamos que essa iniciativa pode motivar e 
incentivar ainda mais o aluno a participar do trabalho proposto. É relevante salientarmos que o professor deve relacionar essas discussões com o conteúdo químico, para que o caso não se torne algo separado e tido apenas como uma curiosidade à parte.

\subsubsection{Caso 2}

Outro caso construído por um grupo de professores refere-se à instalação de uma termelétrica, como pode ser visto adiante:

A nossa história acontece em uma pequena cidade, localizada no interior de Minas, por onde passa um rio. Esse rio não tem nenhum sinal de poluição e uma termelétrica se instalou nessa cidade. Após certo tempo de funcionamento, houve uma mortandade muito grande de peixes nesse rio. Nesse ponto, a questão a ser analisada pelos alunos refere-se à investigação de qual seria a possível causa da morte dos peixes.

Com base no que foi relatado pelo grupo, discutimos com os demais docentes, que também consideraram a história interessante. Isso porque o caso permite dialogar sobre vários assuntos e conteúdos, podendo abordar inclusive o conceito de solubilidade e de equilíbrio químico, pois, quando a temperatura aumenta, ocorre a diminuição de oxigênio solúvel e, então, um deslocamento no equilíbrio e uma consequente alteração na concentração de oxigênio disponível. Debatemos também a relevância desse tema, pelo qual é possível discutir assuntos diretamente ligados às questões de meio ambiente e de sustentabilidade. Além das possíveis fontes de energia, pensando sobre quais deverão ser usadas - levando em conta os benefícios e malefícios/riscos da implantação de diferentes tipos - em distintas regiões, dentre outros.

O caso construído pelo grupo foi considerado pertinente, podendo ser utilizado no ensino médio de modo satisfatório. Apresenta características marcantes de um bom caso, tal como ser evocativo, possibilitando discussões em torno da abordagem CTS. Logo, é sustentável, de forma a permitir questionamentos importantes ao longo de toda atividade (GRAHAM, 2010).

O caso 2 traz ainda aspectos que Herreid defende, como: desperta o interesse pela questão, força uma decisão, tem utilidade pedagógica, é relevante, etc. Entretanto, a história foi muito curta e 
apresentou poucos detalhes acerca do problema, o que acaba por expandir muito as opções e pode gerar dificuldades e, até mesmo, frustração do aluno frente a muitas alternativas.

Além disso, a narrativa não possuía personagens, característica marcante dos casos que conferem mais realidade à história. Com uma narração mais detalhada, o caso poderia levar os alunos a um questionamento bem produtivo em sala de aula, levantando questões éticas, ambientais, econômicas, etc., uma vez que se trata de um tema que permite estabelecer relações entre ciência, tecnologia e sociedade.

\subsection{3. $\operatorname{Caso} 3$}

O terceiro grupo também construiu um caso referente ao tema "hábitos alimentares":

Há quatro anos, três estudantes do ensino médio estão juntos na mesma escola: Caio, Patrícia e Lucas. Todos praticavam natação e tinham uma alimentação saudável e regular, não consumiam bebidas alcoólicas e comidas do tipo fastfood. Porém, após provarem as guloseimas que os colegas de turma levavam, decidiram também levar balas, pirulitos, pipocas, refrigerantes para se alimentarem na escola. Depois de um tempo, Patrícia, que já estava "viciada" em chicletes, começou a reclamar de uma "queimação" constante no estômago; apavorada, perguntou aos amigos se eles também tinham aqueles sintomas. Como os seus amigos não apresentavam tais incômodos, Lucas, cuja mãe era professora de química para o ensino médio, resolveu perguntar o motivo. Após dar-Ihe uma "bronca" pelas guloseimas, a mãe ficou de olhar quais seriam os motivos, já que, dentro de sua matéria, ela estava ministrando acidez e basicidade das substâncias.

O grupo mencionou que, nesse caso, seria questionado aos alunos o porquê da dor de estômago, discutindo os conceitos de $\mathrm{pH}$, de acidez, de basicidade e abordando a formação de gases no estômago. Ao mostrar o caso, o grupo também discutiu a questão da proibição da venda de guloseimas nas escolas, a qual deveria ter como objetivo propiciar uma alimentação mais saudável aos estudantes. Logo, através desse caso, os professores poderiam conscientizar os alunos quanto à sua alimentação no intervalo escolar, gerando um debate ligado à obesidade. Além disso, os docentes sugeriram a possibilidade de abordar equilíbrio químico e poder calórico dos alimentos 
em termoquímica. Por fim, citaram a questão do surgimento das cáries como mais uma opção para discussão durante a resolução do caso.

Em uma análise mais geral, podemos dizer que o caso apresentado é atual e próximo à realidade dos alunos; afinal, é uma situação que eles vivenciam todos os dias na escola. Tem também utilidade pedagógica, permitindo a discussão de vários assuntos, dentre os quais muitos conteúdos químicos, além de convidar os estudantes a ampliarem sua investigação. Assim, o grupo de professores demonstrou entender bem a proposta, trazendo tópicos interessantes e importantes para serem discutidos em sala de aula. Além disso, o caso é aberto, possibilitando mais de uma solução, e evocativo, instigando a discussão (HERREID, 1998A; GRAHAM, 2010).

\subsection{4. $\operatorname{Caso} 4$}

O último grupo optou pelo modelo de Caso Simulado; uma variante da EEEC que apresenta, em seu formato de aplicação, um cenário de júri. Nesse cenário é estabelecido um tema controverso, que permita um debate entre atores (representados pelos alunos) favoráveis e desfavoráveis a uma ideia. Esse grupo não redigiu uma história, apenas citou a sua ideia, cuja descrição segue abaixo:

A proposta voltou-se para a questão da proibição de sacolas plásticas nos supermercados, proporcionando um debate sobre esse assunto. $\mathrm{O}$ grupo pretendia discutir o fato das prefeituras de algumas cidades do país terem aprovado a lei de proibição do fornecimento de sacolas plásticas em supermercados desde janeiro de 2012, sem oferecerem opções para o cliente. A proposta do debate era que houvesse pessoas favoráveis e pessoas contrárias a essa proibição.

Uma professora, pertencente ao grupo, representou um cidadão favorável a essa proibição, relatando a seguinte opinião:

Eu sou a favor da proibição devido aos altos níveis de poluição das sacolas plásticas. Elas causam degradação do ambiente e desordem do clima em geral, dizimam espécies aquáticas e muito mais. Então, eu defendo a completa eliminação do uso de sacos plásticos para embalar as compras em supermercados. 
Essa professora também citou que os profissionais ambientalistas poderiam ser trazidos para 0 debate, visto que apoiam a proibição das sacolas. Já outro professor, que representou uma pessoa contrária à proibição, argumentou da seguinte forma:

A sacola causa problemas de poluição sim, mas não é só a sacola o problema da poluição. Sendo assim, o que as redes de supermercado estão fazendo é jogar o problema para os consumidores. [..] se o supermercado está retirando a embalagem plástica, tem que colocar alguma embalagem que faça com que o consumidor leve o produto até a sua casa ou deve se responsabilizar por entregar o produto na casa do cliente. Pois, se você compra uma geladeira ou um fogão, ele vem todo embalado, porque se danificar o produto a empresa vai ser responsável por isso. [...] o supermercado diminuiu o custo, não precisando mais comprar as sacolinhas. Então, para o supermercado é bom isso. Mas, e para o consumidor? $\mathrm{O}$ consumidor compra o produto, mas como ele o leva para casa? [...] Eu tenho feito algumas pesquisas e a maioria das sacolas, usadas nos supermercados brasileiros, demora de três a cinco anos para desintegrar. Em contrapartida, nós temos plásticos aí que demoram mais de cem anos para desintegrar.

Esse grupo trouxe uma proposta interessante, pois trata de um tema atual e polêmico, que atinge grande parte da população e é, portanto, bem próximo dos alunos. Além disso, optaram por um formato distinto dos outros grupos. O formato de caso simulado permite que haja uma grande discussão por parte dos estudantes, propiciando a argumentação dos mesmos, com a finalidade de defender um posicionamento. Torna-se, assim, mais uma opção, dentre os formatos de aplicação do Estudo de Caso, para o professor da educação básica adotar em suas aulas.

Porém, é importante nesse formato um material de apoio para os estudantes, que demonstre a questão problema formalmente e traga critérios positivos e negativos da mesma. Flôr (2007) atenta para a necessidade dessa documentação, sugerindo o uso de notícias de jornais fictícias, bem como verídicas, informações de livros didáticos e paradidáticos. O uso de depoimentos de especialistas, vídeos explicativos e reportagens em revistas também pode ser uma boa opção.

Destarte, os professores conseguiram construir bons casos, sendo bem criativos. Nota-se, entretanto, a necessidade de uma atenção maior no momento de redigir as histórias, pois as 
mesmas encontram-se inacabadas e não tão bem estruturadas. Porém, isso pode ser atribuído ao reduzido tempo que foi fornecido aos docentes para a criação dos casos e ao acesso a poucos materiais de consulta. A essência da atividade aqui discutida, contudo, foi bem colocada em todos os casos, de modo que eles podem ser abordados em turmas de ensino médio.

Durante as apresentações dos docentes salientamos que os casos não permitem, por si só, a construção do conhecimento pelo aluno. Apesar de ser uma atividade na qual o estudante participa ativamente, o professor deve saber se posicionar durante as resoluções do caso, propiciando discussões relevantes para toda a turma, questionando o aluno e aguçando a capacidade argumentativa do mesmo (SÁ e QUEIROZ, 2010).

\section{CONSIDERAÇÕES FINAIS}

Em uma análise mais ampla e coerente das questões sobre as quais incidiram o minicurso, vê-se que o projeto conseguiu atingir o seu objetivo primordial: divulgar a EEEC, trazendo mais uma opção de instrumento de ensino a ser adotada pelos professores da educação básica. Os docentes entenderam a essência da atividade divulgada e as características que permeiam a elaboração de um caso investigativo, além de como se dá a sua resolução. Eles também demonstraram interesse pela atividade, declarando que ela tinha potencial para ser aplicada nas aulas de química no ensino médio e que seria uma opção de estratégia de ensino que eles utilizariam em suas turmas.

Durante todo o evento salientamos a conduta do professor como um fator determinante para o sucesso da atividade, o que nos remete à necessidade de rever a formação dos professores para a educação básica, propiciando mais cursos de formação continuada. Dentre esses cursos, destacamos os que abordam estratégias de ensino inovadoras para a sala de aula, de forma que se atentem também para o papel do professor.

Um contato maior entre a universidade e a escola permitirá que essas mudanças, na formação do professor, ocorram de modo mais efetivo. No decorrer do minicurso foi possível perceber o contentamento dos professores em participar do evento e a ênfase dada por eles à relação universidade-escola. Eles alegaram que deveria haver mais projetos que, como esse, envolvesse os professores da educação básica, os professores da graduação e da pós-graduação, bem como, graduandos e pós-graduandos; visto que todos buscam atender ao objetivo de melhorar o ensino nas escolas e de preparar o estudante para a vida. 
Por fim, esperamos que, mesmo diante de uma carga-horária pequena, esse minicurso tenha contribuído positivamente para a formação dos docentes participantes, de forma que eles sintamse mais motivados e engajados na tentativa de introduzir novas estratégias de ensino no espaço escolar; com destaque para a Estratégia de Ensino Estudo de Caso. Sabe-se que, dentre tantos outros professores e tantos caminhos a percorrer, esses docentes ainda representam uma pequena parcela, mas acreditamos, em consonância com a afirmativa de Ático Chassot (2007, p. 47), que: "quanto mais pessoas sonharem os nossos sonhos, mais provavelmente estes se transformarão em realidades. E o amanhã se fará hoje mais rapidamente".

\section{REFERÊNCIAS}

ACEVEDO, J. A. La Formacion del professorado de enseñanza secundara y la educacion CTS. Uma cuestion problematica. Revista Interuniversitaria de Formación del Profesorado,Zaragoza, n. 26, p. 131-144, 1996.

BOGDAN, R.; BIKLEN, S. Investigação qualitativa em educação: uma introdução à teoria e aos métodos. Porto: Porto Editora, 336p, 1994.

BRASIL. Lei de Diretrizes e Bases da Educação Nacional, Lei n9.394, 20 de dezembro de 1996.

Parâmetros Curriculares Nacionais do Ensino Médio. Ciências da Natureza, Matemática e suas tecnologias. Brasília: Ministério da Educação e do Desporto, 2002.

BRITO, J. Q. A.; SÁ, L. P. Estratégias promotoras da argumentação sobre questões sócio-científicas com alunos do ensino médio. Revista Electrónica de Enseñanza de lãs Ciencias, v. 9, n. 3, p. 505-529, 2010.

CHASSOT, A. Educação ConSciência. 2.ed Santa Cruz do Sul: EDUNISC, 2007.

CARVALHO, A. M. P.; GIL-PÉREZ, D. Formação de professores de ciências: tendências e inovações. 10. ed. São Paulo: Cortez Editora, 2011.

FARIA, F. L. Estudo de Casos e o desenvolvimento de habilidades cognitivas pelos alunos do ensino médio. Monografia (Licenciatura em Química), Universidade Federal de Viçosa, Viçosa, 2011.

FARIA, F. L.; SILVA, A. F. A. Estudo de Casos e o desenvolvimento de habilidades cognitivas pelos alunos do ensino médio. Anais do XVI Encontro Nacional de Ensino de Química e X Encontro de Educação de Química da Bahia. 17-20 jul, 2012.

FLÔR, C. C. Possibilidades de um caso CTS na discussão da poluição ambiental. Ciência \& Ensino, Campinas, v.1, número especial, 2007.

GIL, A.C. Método e técnicas de pesquisa social. 5a ed. São Paulo: Atlas, 1999.

GRAHAM, A. Estudo de Caso: Como escrever e usar estudos de caso para o ensino e aprendizagem no setor público. Brasília: ENAP, 2010.

HERREID, C.F. What's makes a good case? Journal of College Science Teaching, Arlington, v. 27, n. 3, p. 163-165, 1998a. 
Faria, Freitas-Reis, 2016 - Formação Inicial e Continuada

1998b.

. Sorting Potatoes for Miss Bonner. Journal of College Science Teaching, Arlington, v. 27, n. 4, p. 236-239,

. The Death of problem-based learning? Journal of College Science Teaching, Arlington, v. 32, n. 6, p. 364-

$366,2003$.

. Can cases studies be used to teach critical thinking. Journal of College Science Teaching, Arlington, v. 33, n. 1, p. 12-14, 2004.

LUDKE, M.; ANDRÉ, M. E. D. A. Pesquisa em educação: abordagens qualitativas. São Paulo: EPU, 1986.

MALDANER, O. A. A formação inicial e continuada de professores de Química. 3. ed. Ijuí: Editora Unijuí, 2010.

OLIVEIRA, A. S.; SOARES, M. H. F. B. Júri Químico: Uma atividade lúdica para discutir conceitos químicos. Química Nova na Escola, São Paulo, n. 21, p.18-24, 2005.

PINHEIRO, N.A.M.; SILVEIRA, R.M.C.; BAZZO, W.A. Ciência, Tecnologia e Sociedade: A relevância do enfoque CTS para o contexto do Ensino Médio. Ciência \& Educação, Bauru, v. 13, n. 1, p. 71-84, 2007.

. O contexto científico-tecnológico e social acerca de uma abordagem crítico-reflexiva: perspectiva e enfoque. Revista Iberoamericana de Educação, v. 1, n. 49, 2009.

SÁ, L. P. A argumentação no ensino superior de química: investigando uma atividade fundamentada em estudos de casos. Instituto de Química de São Carlos. Universidade de São Paulo. Dissertação (Mestrado em Ciências), 2006.

SÁ, L. P.; QUEIROZ, S. L. Casos investigativos como estratégia para o desenvolvimento de habilidades cognitivas e da capacidade de tomada de decisão de alunos de graduação em Química. Associação Brasileira de Pesquisa em Educação em Ciências. Atas do V ENPEC, 5, 2005.

SÁ, L. P.; FRANCISCO, C. A.; QUEIROZ, S. L. Estudo de Caso em Química. Química Nova, São Paulo, v.30, n.3, p.731-739, 2007.

SÁ, L. P.; QUEIROZ, S. L. Estudo de Caso no Ensino de Química. 2a Ed., São Paulo: Editora Átomo, 2010.

SANTOS, W. L. P.; MORTIMER, E. F. Uma análise de pressupostos da abordagem C-T-S (Ciência-Tecnologia-Sociedade) no contexto da educação brasileira. Ensaio - Pesquisa em Educação em Ciências, Belo Horizonte, v. 2, n. 2, p.1-23, 2002.

Tomada de decisão para ação social responsável no Ensino de Ciências. Ciência \& Educação, Bauru, v.7, n.1, p.95-111, 2001.

SANTOS, W. L. P.; SCHNETZLER, R. P. Educação em Química: Compromisso com a cidadania.4ạ ed. ljuí: Editora Unijuí, 2010.

SANTOS, W. L. P.; GAUCHE, R.; MÓL, G. S.; SILVA, R. R.; BAPTISTA, J. A. Formação de professores: uma proposta de pesquisa a partir da reflexão sobre a prática docente. Ensaio - Pesquisa em Educação em Ciências, Belo Horizonte, v.8, n.1, p.69-82, 2006.

SILVA, O. B.; OLIVEIRA, J. R. S.; QUEIROZ, S. L. SOS Mogi-Guaçu: Contribuições de um Estudo de Caso para a educação química no ensino médio. Química Nova na Escola, São Paulo: v.33, n.3, p.185-192, 2011. 